\title{
Design, implementation and validation of a motorized wedge filter for a telecobalt machine (Bhabhatron-II)
}

\author{
Rajesh Kumar $^{\text {a,* }}$, D.C. Kar ${ }^{b}$, S.D. Sharma ${ }^{a}$, Y.S. Mayya ${ }^{a}$ \\ ${ }^{a}$ Radiological Physics \& Advisory Division, Bhabha Atomic Research Centre, CTCRS Building, Anushaktinagar, \\ Mumbai-400094, India \\ ${ }^{\mathrm{b}}$ Division of Remote Handling and Robotics, Bhabha Atomic Research Centre, Mumbai-400085, India
}

Received 25 October 2010; received in revised form 28 February 2011; accepted 3 March 2011

Available online 12 April 2011

\author{
KEYWORDS \\ Motorized wedge; \\ Telecobalt; \\ Bhabhatron-II; \\ Wedge beam weight; \\ Wedge factor
}

\begin{abstract}
A universal wedge filter of $15 \mathrm{~W} \times 20 \mathrm{~cm}^{2}$ and $60^{\circ}$ nominal wedge angle is designed and placed between the collimating jaws and penumbra trimmers inside the treatment head. A pneumatically driven actuating mechanism toggles the wedge between the wedge IN position and wedge OUT position. The effective wedge angles were determined using an analytical formula. An accumulated wedge profile at a depth of $10 \mathrm{~cm}$ which was measured using a 2D profiler and dose values at depths of $10 \mathrm{~cm}$ and $20 \mathrm{~cm}$ for the same experimental setup were used as input parameters in the formula used for determining effective wedge angles. The relationship between the wedge beam weight and effective wedge angle was established. The planned wedge angles were compared with the measured wedge angles and the differences are found to be less than $2^{\circ}$ throughout the range of field sizes. Planned doses for various field sizes and wedge angles were measured for verification and the differences were found to be less than $1.8 \%$. This study established that the relationship between the beam weights and effective wedge angles implemented for the motorized wedge filter of medical linacs is not directly applicable for the motorized wedge filter of Telecobalt.
\end{abstract}

(c) 2011 Associazione Italiana di Fisica Medica. Published by Elsevier Ltd. All rights reserved.

\footnotetext{
* Corresponding author. Tel.: +91 22 25598716; fax: +91 2225519209.

E-mail address: raj_resh@rediffmail.com (R. Kumar).
}

1120-1797/\$ - see front matter @ 2011 Associazione Italiana di Fisica Medica. Published by Elsevier Ltd. All rights reserved. doi:10.1016/j.ejmp.2011.03.001 


\section{Introduction}

Telecobalt machines are prominently being used as external beam radiation therapy equipment in the developing and under-developed countries. Although telecobalt units are used effectively for the treatment of cancer, no major research and development works have been carried out for further technological development of this machine. Recently, a new model of telecobalt unit, named Bhabhatron-II [1-4] was developed and introduced for cancer treatment. This unit has a number of advanced features which are hitherto not available in telecobalt machines.

In radiotherapy, wedge filters are extensively used as beam-modifiers to optimize the dose distribution for better dose delivery. Although multiple choices are available for generating wedged dose profiles, physical wedge filters of wedge angles $15^{\circ}, 30^{\circ}, 45^{\circ}$ and $60^{\circ}$ are typically used in telecobalt units. In the motorized wedge filter technique, a desired wedged beam profile (typically up to $60^{\circ}$ wedge angle) can be generated by combining the wedged and open beam in appropriate proportions. The motorized wedge filter has a number of advantages, viz. no probability of physical injury to operators and patient, it is no longer necessary to handle physical wedges, making wedge selection faster and easier, which results in higher patients throughput and less fatigue for operators and flexibility to generate arbitrary wedge angle instead of the limited standard angles. Clinical commissioning of a motorized wedge filter for a Theratron Equinox telecobalt unit has been reported in the literature [5-7]. In the Bhabhatron-II, a motorized wedge filter with a nominal wedge angle of $60^{\circ}$ was designed, fabricated, implemented and commissioned. So far, the resources regarding the implementation of a motorized wedge filter are available for high energy $x$-raysgenerated by a medical linac. But the scatter component at the depth of interest for a wedge filter is quite different for Co-60 gamma rays. Thus, it is important to carry out a comprehensive study for implementation of a motorized wedge on a telecobalt machine. This paper describes the design, implementation and performance evaluation of a motorized wedge filter for the Bhabhatron-II telecobalt unit.

\section{Material and methods}

\section{Bhabhatron-II telecobalt unit}

The Bhabhatron-II is an isocentric (source to isocentre distance $=80 \mathrm{~cm}$ ) telecobalt machine which incorporates various advanced features such as (i) availability of a very small $\left(0.5 \times 0.5 \mathrm{~cm}^{2}\right)$ treatment field size, (ii) fully computer controlled operations with patient and treatment data management capability, (iii) automatic and full $\left(0.5 \times 0.5 \mathrm{~cm}^{2}\right)$ closure of collimator in case of functional abnormality, (iv) provision for auto patient setup, (v) remote monitoring of the machine status, and (vi) asymmetric collimator. The source head of Bhabhatron-Il consists of a stainless steel shell filled with lead and depleted uranium (or tungsten) which can house $\mathrm{a}^{60} \mathrm{Co}$ source of strength up to $555 \mathrm{TBq}(15 \mathrm{kCi} \approx 250 \mathrm{RMM})$. A cylindrical source capsule securely mounted inside a cylindrical source drawer is loaded inside the head of this unit. Source transfer between the shielded (radiation OFF) and treatment (radiation ON) position is actuated by a pneumatic drive system. Field limiting devices contain primary (with fixed opening) as well as secondary (with variable opening) collimators. The secondary collimator of this unit consists of two pairs of collimating jaws made of depleted uranium (or tungsten). Two pairs of trimmer bars, also made of depleted uranium (or tungsten) are provided to limit the radiation beam penumbra. The collimator jaws are motor driven and can define square/rectangular field sizes at the isocentre in the range of $0.5 \times 0.5$ to $35 \times 35 \mathrm{~cm}^{2}$. In case of a stuck source, the collimator jaws/trimmers close automatically to $0.5 \times 0.5 \mathrm{~cm}^{2}$. This is an improved design aspect toward radiation safety concerns for patients and radiation workers. All movements of the unit can be interactively controlled using the push-buttons on the panel located on either side of the couch. The unit has a dedicated dual window display monitor installed inside the treatment room where major patient setup parameters are displayed. A remote control console consists of a graphical user interface (GUI) on a personal computer. The treatment prescription of a patient can be loaded against a distinct identification number which can be recalled routinely for treatment delivery. Treatment delivery of a patient is possible only when the set (or prescribed) values and actual values of machine parameters are within the acceptable tolerances.

\section{Design of motorized wedge}

A universal wedge of $15 \mathrm{~W} \times 20 \mathrm{~cm}^{2}$ and $60^{\circ}$ nominal wedge angle using stainless steel (density $7.83 \mathrm{gm} / \mathrm{cc}$ ) was designed and fabricated. It was placed between the collimating jaws and penumbra trimmers inside the collimator assembly. A schematic diagram of the collimator assembly of Bhabhatron-Il with motorized wedge is shown in the Fig. 1. A pneumatically driven actuating mechanism toggles the wedge between the wedge IN position and wedge OUT position. In the normal situation the wedge moves perpendicular to the source motion when the collimator is at $0^{\circ}$ angle. Arbitrary wedge angles can be generated with appropriate combinations of open and wedged beam weights. The $60^{\circ}$ wedge filter was fabricated following the methods suggested in the literature $[8,9]$. These methods are based on the principle of determining the ratio of percentage depth doses of a wedged beam isodose curve and an open beam isodose curve for various points on both sides of the wedge axis. The required wedge profile was determined from this ratio and the attenuation characteristics of stainless steel for ${ }^{60} \mathrm{Co}$ gamma rays [10].

\section{Experimental setup}

The effective wedge angles for various combination of open and wedge beam weights were determined using the following formula [11]:

$$
\theta_{\mathrm{E}}=\arctan \left(\frac{\ln \left(\frac{\mathrm{D} 1}{\mathrm{D} 2}\right)}{0.5 \times \mathrm{FS} \times \mu}\right)
$$




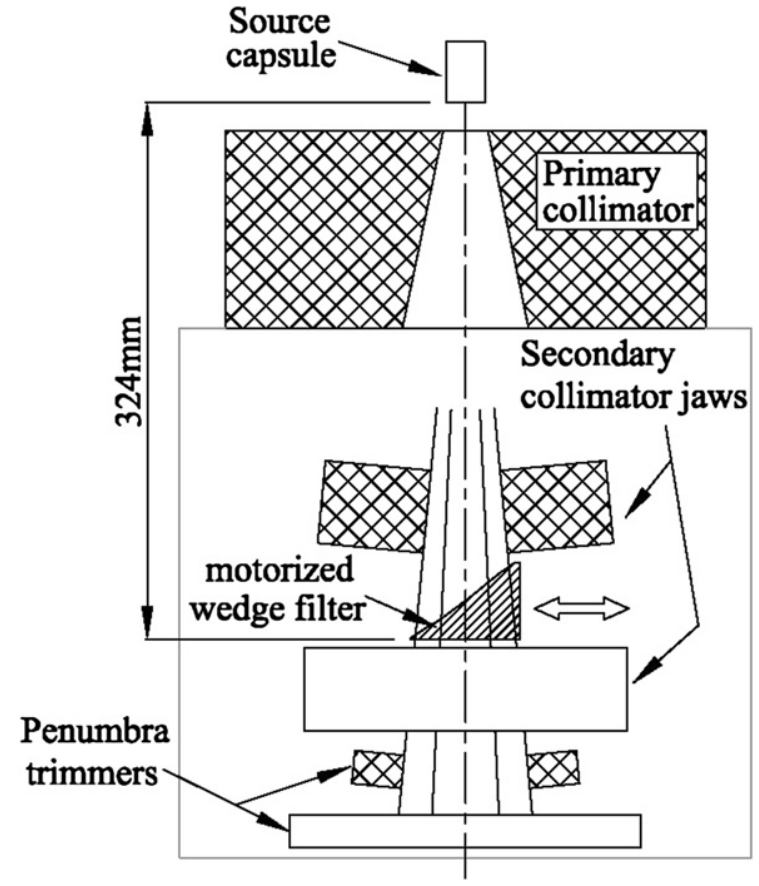

Figure 1 Schematic diagram of the collimator assembly of Bhabhatron-II with motorized wedge indicating location of motorized wedge.

where FS is the field size in $\mathrm{cm}, \mathrm{D} 1, \mathrm{D} 2$ are the dose values at positions $+0.25^{*} \mathrm{FS}$ and $-0.25 * \mathrm{FS}$ at the depth of $10 \mathrm{~cm}$, and $\mu=0.1 \times \ln (\mathrm{d} 10 / \mathrm{d} 20)$ where $\mathrm{d} 10$ and $\mathrm{d} 20$ are the dose values at depths $10 \mathrm{~cm}$ and $20 \mathrm{~cm}$ respectively for the same field size and the beam weight.

Beam profiles for various field sizes in the range of $5 \mathrm{~W} \times 5$ to $15 \mathrm{~W} \times 20 \mathrm{~cm}^{2}$ were measured using a $2-\mathrm{D}$ beam profiler (StarTrack, IBA Dosimetry, Sweden) by setting the sampling time greater than the beam ON time. The profiles were analyzed using the dedicated software of the profiler (OmniPro-Advance, IBA Dosimetry, Sweden). To determine D1 and D2, the accumulated dose profiles resulting from irradiation of open and wedged beams were measured by placing solid water slabs of thicknesses $10 \mathrm{~cm}$ on the front surface of the 2D beam profiler with appropriate back scattering condition as shown in Fig. 2. Profiles for various combinations of wedged beam weights and field sizes were generated in the similar manner. Dose values corresponding to d10 and d20 were measured in a full scatter water phantom of size $30 \times 30 \times 30 \mathrm{~cm}^{3}$ at the depth of $10 \mathrm{~cm}$ and $20 \mathrm{~cm}$, respectively using a $0.63 \mathrm{~cm}^{3}$ Farmer type ionization chamber and the associated electrometer (A19 Exradin and CDX 2000B, Standard Imaging, USA) under the source to surface distance(SSD) setup. The experiments were repeated for various combinations of wedged beam weights and field sizes.

The wedge angle calculated using equation (1) was also verified as per the definition of ICRU 24 [12] which defines wedge angle as the complement of the angle between the central axis and a line tangent to the isodose curve at the depth of $10 \mathrm{~cm}$. For any given combination of open and wedge beams, resultant profiles were measured at a number of depths by placing solid water slabs of corresponding thicknesses over frontal surface of the $2 \mathrm{D}$ beam profiler under the

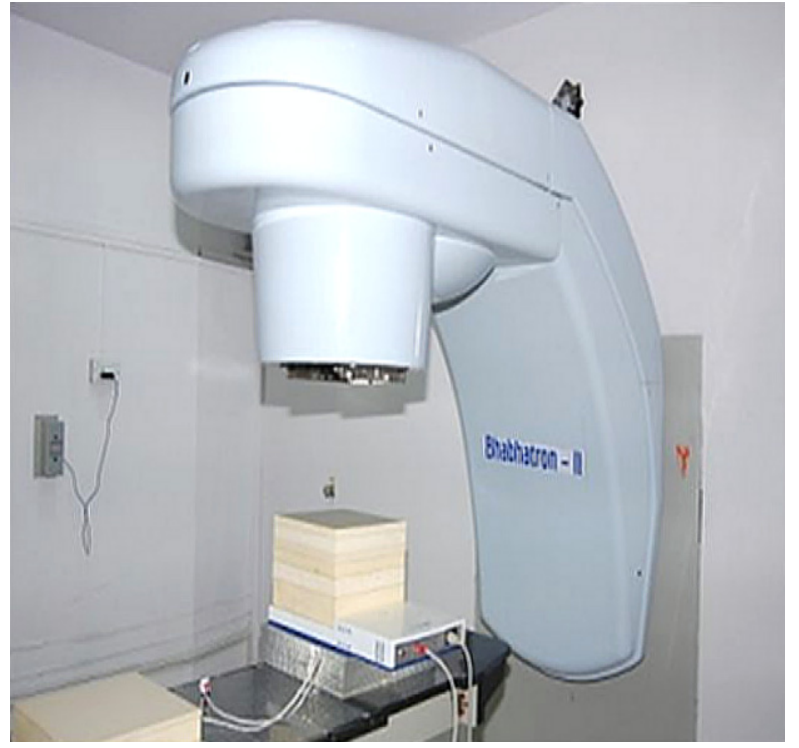

Figure 2 Experimental setup for beam profile measurements using $2 \mathrm{D}$ beam profiler.

suitable back scattering condition. A computer program was developed in Delphi 7.0 to convert the profile data to a format acceptable by radiation beam analysis software (MEPHYSTO mc $^{2}$; PTW, Germany) for generating the isodose curves, and subsequently to determine the wedge angle.

\section{Implementation}

If $B$ is the wedged beam weight (fraction of the treatment time for which the wedge should be in the path of the beam) for a desired wedge angle, then

$\mathrm{D}=(1-\mathrm{B}) \cdot \mathrm{D}_{\mathrm{o}}+\mathrm{B} \cdot \mathrm{D}_{\mathrm{w}}$

where $D$ is the desired wedged dose distribution; $D_{0}=$ open beam dose distribution, and $D_{w}$ is the wedged dose distribution corresponding to the nominal wedge angle of the wedge filter.

The wedged beam weight $B$ can be determined as [13]:

$B=f /\left(\left(\tan \theta_{\mathrm{w}} / \tan \theta_{\mathrm{E}}\right)+f-1\right)$

where $\theta_{\mathrm{E}}$ effective wedge angle; $\theta_{\mathrm{w}}$ is the nominal wedge angle of the motorized wedge filter, and $f$ is a fitting parameter to be determined from the measured values of effective wedge angles.

For different values of $B(0>B>1)$, at intervals of 0.1 , the effective wedge angles were determined using the equation (1) for a given wedged field size. The beam weights were plotted against the measured effective wedge angles and the equation (3) was fitted using a user defined function feature of Origin Pro 8 to obtain the fitted value of $f$ for the corresponding wedged field size. The experiment was repeated for different field sizes to obtain the field dependent $f$ values.

Control logic was evolved to calculate the wedged beam weight $B$ for combinations of inputs viz. field size and wedge angle by choosing the appropriate value of $f$ determined as detailed above. Accordingly, it is implemented in the control software to determine automatically the 
duration for which the wedge filter should remain in the beam path for the required combinations of the parameters: treatment time, field size, and the required wedge angle. The motorized wedge filter comes to the radiation beam path before the source moves to the beam ON position. Once the duration for the wedged beam is over, the wedge moves back to the parking position. However, the source remains at the beam ON position till the completion of the set treatment time.

\section{Validations}

\section{Wedge angle verifications}

Irradiation setup using wedge angles starting from 5 to the maximum achievable wedge angle in intervals of $5^{\circ}$ for field sizes $5 \times 5,10 \times 10$ and $15 \times 15 \mathrm{~cm}^{2}$ were planned. The wedged beam profiles using the 2-D beam profiler were measured as described in Section 2.3. The measured profiles were analyzed for wedge angle using equation (1).

\section{Wedge factors}

The wedge factor (WF) at depth (d) in water, for a given field size (FS), is defined as the ratio of the dose on the central axis with the wedge in place, DW(FS, d), to the dose without the wedge (open beam), D0 (FS, d):

$\mathrm{WF}(\mathrm{FS}, \mathrm{d})=\mathrm{D}_{\mathrm{W}}(\mathrm{FS}, \mathrm{d}) / \mathrm{D}_{\mathrm{0}}(\mathrm{FS}, \mathrm{d})$

Dose values for determining the wedge factor were measured using IAEA TRS 398 protocol [14] in a full scatter water phantom of size $30 \times 30 \times 30 \mathrm{~cm}^{3}$ at the depth of $5 \mathrm{~cm}$ under SSD setup for $15,30,45$ and $60^{\circ}$ wedge angles for $5 \times 5$, $10 \times 10$ and $15 \times 15 \mathrm{~cm}^{2}$ field sizes using a secondary standard dosimeter comprising a $0.63 \mathrm{~cm}^{3}$ Farmer type ionization chamber and an electrometer. All measurements were taken with the collimator rotated such that the chamber axis was oriented perpendicular to the wedge direction, thus avoiding any gradient along the chamber axis.

\section{Reproducibility of wedge positioning}

For estimation of reproducibility of wedge positioning, the dose values were measured in the water phantom at $5 \mathrm{~cm}$ depth under SSD setup for $45^{\circ}$ wedge angle and $10 \times 10 \mathrm{~cm}^{2}$ field size using the secondary standard dosimeter. Twenty five consecutive measurements were performed keeping

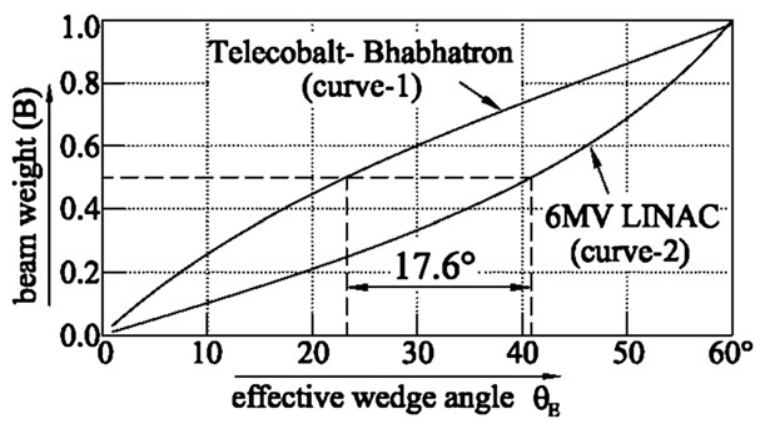

Figure 3 Comparison of plots for effective wedge angle versus wedged beam weight of telecobalt (curve-1) and published methodology of linear accelerators (curve-2) for motorized wedge filter.
Table 1 Effective wedge angles for the various wedged beam weights at different field sizes.

\begin{tabular}{lccc}
\hline $\begin{array}{l}\text { Wedge beam } \\
\text { weight }\end{array}$ & \multicolumn{2}{c}{ Effective wedge angle for field size $\left(\mathrm{cm}^{2}\right)$} \\
\cline { 2 - 4 } & $5 \times 5$ & $10 \times 10$ & $15 \times 15$ \\
\hline 0 & 0.0 & 0.0 & 0.0 \\
0.1 & 2.5 & 3.3 & 3.9 \\
0.2 & 5.3 & 6.9 & 8.2 \\
0.3 & 10.3 & 11.7 & 12.7 \\
0.4 & 14.8 & 16.9 & 18.5 \\
0.5 & 19.7 & 21.8 & 23.6 \\
0.6 & 26.5 & 28.2 & 31.0 \\
0.7 & 33.1 & 34.7 & 37.3 \\
0.8 & 39.3 & 42.5 & 44.5 \\
0.9 & 47.7 & 47.7 & 53.2 \\
1.0 & 52.8 & 59.4 & 59.8 \\
\hline
\end{tabular}

the same experimental condition. The wedge position reproducibility was calculated in terms of coefficient of variation of the twenty five measurements.

\section{Influence of gravity}

To investigate the influence of gravity on the movement of the motorized wedge, the dose values were measured at 0 , 90,270 and $180^{\circ}$ gantry angles in air for $30^{\circ}$ wedge angle and $10 \times 10 \mathrm{~cm}^{2}$ field size using secondary standard dosimeter. The influence of the gravity was estimated by comparing the ratio of dose with and without the wedge in comparison of $0^{\circ}$ gantry angle. Here it was assumed that one angle and one field size can be considered as the representative to the influence of the gravity on the wedge movement for entire wedge angles and field sizes.

\section{Verifications of planned dose with wedge}

An irradiation simulating clinical treatment to deliver a prescribed dose of $1.0 \mathrm{~Gy}$ at the depth of $5 \mathrm{~cm}$ in full scatter water phantom in SSD setup using $15^{\circ}$ wedge angle and $10 \times 10 \mathrm{~cm}^{2}$ field size was planned. The phantom was irradiated and the dose delivered to the point of interest was measured using secondary standard dosimeter. The experiment was repeated for the wedge angles of 30,45 and $55^{\circ}$. Further the experiment was also repeated for field sizes $5 \times 5$ and $15 \times 15 \mathrm{~cm}^{2}$.

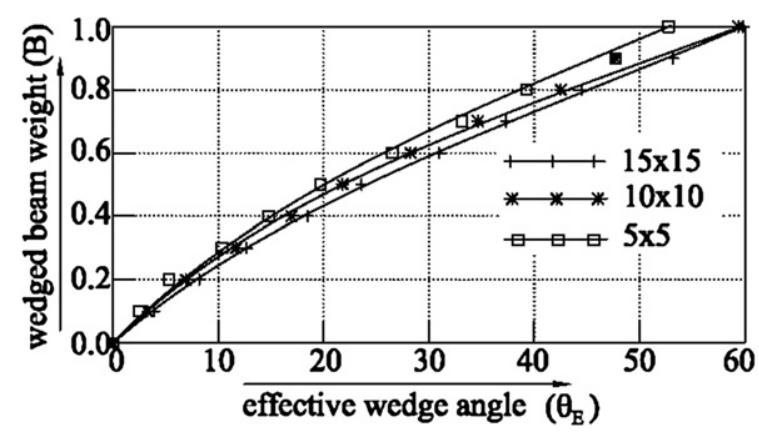

Figure 4 Effective wedge angle versus wedged beam weight for different field sizes. Continuous curves represent corresponding fitted equations. 


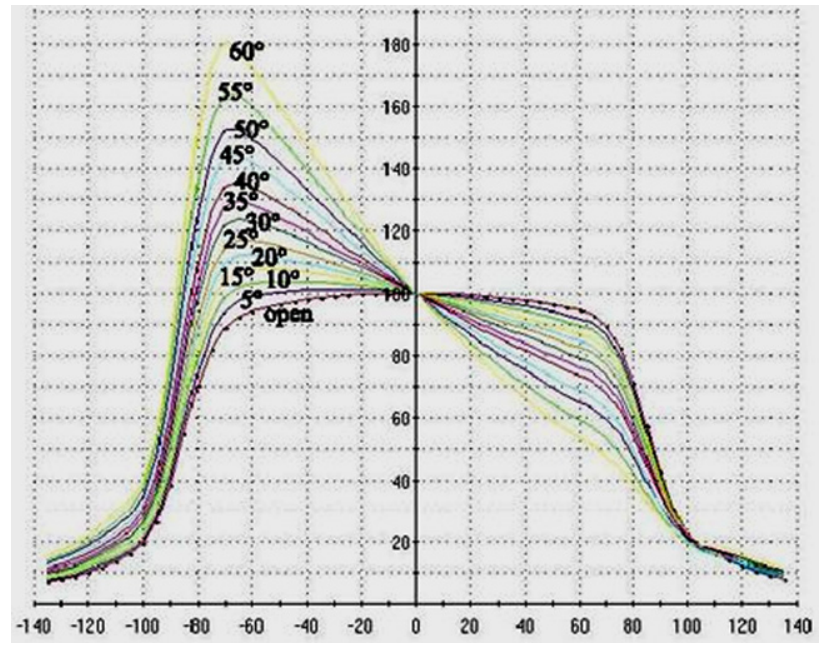

Figure 5 Open and wedge beam profile for various angle generated using motorized wedge measured at depth $10 \mathrm{~cm}$.

\section{Results and discussion}

The effective wedge angle $\left(\theta_{\mathrm{E}}\right)$ is plotted against wedges beam weights $(B)$ for $15 \times 15 \mathrm{~cm}^{2}$ field, as shown in Fig. 3 . It is observed that initially $\theta_{\mathrm{E}}$ increases at a slower rate with $B$, and gradually the trend reverses. This behavior is in contrast with the published data $[15,16]$ for motorized wedge filter of linear accelerators. This difference is attributed primarily due to the difference in energy spectrum. Another significant factor is due to the additional scatter that is generated in a cobalt beam compared to higher energy medical linac beams. This study reveals that the relationship between the beam weights and effective wedge angles for the motorized wedge filter of medical linacs is not directly applicable for the motorized wedge filter of telecobalt. To achieve the proper wedge profile using a motorized wedge in telecobalt units, an exclusive relation between wedge beam weight and wedge angle needs to be established.

Table 1 shows the variation of $\theta_{\mathrm{E}}$ against beam weights $\mathrm{B}$ for different field sizes. It is observed that $\theta_{\mathrm{E}}$ varies with field size

Table 2 Planned and measured wedge angle as per equation (1) for $15 \times 15 \mathrm{~cm}^{2}$ field sizes.

\begin{tabular}{lcc}
\hline Planned wedge angle & $\begin{array}{l}\text { Measured wedge } \\
\text { angle }\end{array}$ & $\begin{array}{l}\text { Deviation in } \\
\text { degree }\end{array}$ \\
\hline 5 & 5.3 & 0.2 \\
10 & 10.0 & -0.3 \\
15 & 15.2 & 0.2 \\
20 & 19.7 & -0.5 \\
25 & 25.2 & -1.2 \\
30 & 29.5 & -0.4 \\
35 & 33.8 & -1.6 \\
40 & 39.6 & -1.8 \\
45 & 43.4 & -1.0 \\
50 & 48.2 & -0.6 \\
55 & 54.0 & 0.2 \\
60 & 59.4 & -0.3 \\
\hline
\end{tabular}

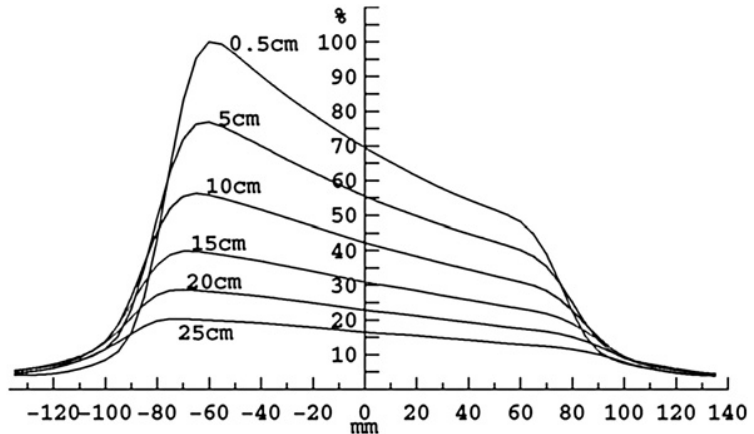

Figure 6 Wedge profiles generated using motorized wedge for $40^{\circ}$ wedge angle at the different depths (i.e. 0.5, 5.0, 10.0, $15.0,20.0$ and $25.0 \mathrm{~cm}$ ) for the field size of $15 \times 15 \mathrm{~cm}^{2}$.

also. However, the influence of the field size on $\theta_{\mathrm{E}}$ is small. The values were plotted as shown in Fig. 4 for different field sizes viz. $5 \times 5,10 \times 10$ and $15 \times 15 \mathrm{~cm}^{2}$. This figure also shows the curves (solid lines) obtained by fitting the measured $\theta_{\mathrm{E}}$ and $\mathrm{B}$ as per equation (2), and the value of the parameter $f$ was determined for each field. For field sizes of $5 \times 5,10 \times 10$ and $15 \times 15 \mathrm{~cm}^{2}, f$ was found to be $2.594,3.246$ and 2.846 respectively. Although the wedge filter was designed to be universal, the maximum wedge angle of $60^{\circ}$ (for $B=1.0$ ) deviates from this, particularly at smaller field size e.g. preset $60^{\circ}$ wedge angle was measured as 52.8, 59.4 and 59.8 for field sizes $5 \times 5,10 \times 10$ and $15 \times 15 \mathrm{~cm}^{2}$ respectively. This field size dependency of the effective wedge angle was taken into consideration and the following method was devised. The wedged field is divided into three segments namely; a) field size (FS) $\leq 7.5 \times 7.5 \mathrm{~cm}^{2}$, b) $7.5 \times 7.5 \mathrm{~cm}^{2}<$ $\mathrm{FS} \leq 12.5 \times 12.5 \mathrm{~cm}^{2}$, and c) FS $>12.5 \times 12.5 \mathrm{~cm}^{2}$. Accordingly, the parameter $f$ is set as 2.594, 3.246 and 2.846 respectively. During operation, the user needs to provide the parameters prescribed by the clinician such as field size and motorized wedge angle, treatment time etc. The control software automatically determines the required wedged beam weight for the combination of required wedge angle and the field size.

The wedged beam profiles were measured at $10 \mathrm{~cm}$ depth for different field sizes for different wedge angles.

Table 3 Comparison of planned wedge angle and wedge angle as per the definition of ICRU 24 using the isodose curve for $15 \times 15 \mathrm{~cm}^{2}$ field size.

\begin{tabular}{llr}
\hline $\begin{array}{l}\text { Planned wedge } \\
\text { angle }\end{array}$ & $\begin{array}{l}\text { Wedge angle as per } \\
\text { ICRU 24 }\end{array}$ & Deviation in degree \\
\hline 5 & 05.1 & 0.1 \\
10 & 09.5 & -0.5 \\
15 & 15.8 & 0.8 \\
20 & 20.3 & 0.3 \\
25 & 26.1 & 1.1 \\
30 & 30.6 & 0.6 \\
35 & 35.8 & 0.8 \\
40 & 41.7 & 1.7 \\
45 & 44.7 & -0.3 \\
50 & 52 & 2.0 \\
55 & 56.7 & 1.7 \\
60 & 62.0 & 2.0 \\
\hline
\end{tabular}


Table 4 Motorized wedge factor for various field sizes.

\begin{tabular}{lllll}
\hline Wedge & & Motorized wedge factor \\
\cline { 2 - 5 } angle & $5 \times 5 \mathrm{~cm}^{2}$ & $10 \times 10 \mathrm{~cm}^{2}$ & $15 \times 15 \mathrm{~cm}^{2}$ & $15 \times 20 \mathrm{~cm}^{2}$ \\
\hline 15 & 0.71 & 0.76 & 0.78 & 0.80 \\
30 & 0.55 & 0.61 & 0.64 & 0.65 \\
45 & 0.43 & 0.48 & 0.51 & 0.52 \\
60 & 0.36 & 0.37 & 0.39 & 0.39 \\
\hline
\end{tabular}

Fig. 5 shows the profiles for open as well as wedged beams for $15 \times 15 \mathrm{~cm}^{2}$ field. Effective wedge angle for each profile was determined using equation (1) for verification of the planned wedge angle. Table 2 shows the planned and measured wedge angles for $15 \times 15 \mathrm{~cm}^{2}$ field size and their deviation. It is observed that the maximum deviation between the planned and measured wedge angle was $2^{\circ}$ throughout the range of field sizes.

Figure 6 shows the measured wedge profiles at a different depth of $0.5,5.0,10.0,15.0,20.0$ and $25.0 \mathrm{~cm}$ for the field size of $15 \times 15 \mathrm{~cm}^{2}$. Table 3 shows the comparison of planned wedge angle and wedge angle determined from the isodose curve as per ICRU 24 definition. Here also, the maximum difference between the planned and measured wedge angles was found to be $2^{\circ}$.

Table 4 shows the wedge factors for combinations of wedge angles and field sizes. These factors can be used for the treatment time calculation to account for the attenuation in the beam intensity due to the presence of the wedge filter in the radiation beam.

The reproducibility of wedge positioning was determined by estimating the coefficient of variation of the twenty five consecutive measurements and found to be less than 0.05 .

Table 5 shows the influence of the gravity on the movement of the motorized wedge filter. Data shows that the variation of the relative response with gantry angle is within $2 \%$ with respect to zero degree gantry angle.

Table 6 shows the comparison of the planned and measured dose values using the motorized wedge and their variation. It is observed that the planned and measured dose values are well within $2 \%$ for the various field sizes and wedge angles.

The consideration of transit dose in any telecobalt based treatment is important. In the Bhabhatron-II, the motorized wedge filter comes in the radiation beam path before the source moves to the beam ON position. Once the duration for the wedged beam is over, the wedge moves back to the parking position. However, the source remains at the beam ON position till the completion of the planned treatment. Thus, for any wedge field generated by motorized wedge, the source moves out only once, and accordingly, the motorized wedge does not leave additional contribution to

Table 5 Influence of the gravity on the movement of the motorized wedge.

\begin{tabular}{lll}
\hline Gantry angle & Relative response & \% Variation \\
\hline 0 & 1.00 & - \\
90 & 1.02 & 2 \\
270 & 1.02 & 2 \\
180 & 1.00 & 0 \\
\hline
\end{tabular}

Table 6 Comparison of the planned and measured dose values with motorized wedge.

\begin{tabular}{lllll}
\hline $\begin{array}{l}\text { Field } \\
\text { size }\left(\mathrm{cm}^{2}\right)\end{array}$ & $\begin{array}{l}\text { Motorized } \\
\text { wedge angle }\end{array}$ & $\begin{array}{l}\text { Planned } \\
\text { dose }(\mathrm{Gy})\end{array}$ & $\begin{array}{l}\text { Measured } \\
\text { dose }(\mathrm{Gy})\end{array}$ \\
\hline $5 \times 5$ & 15 & 1 & 1.02 & 1.02 \\
& 30 & 1 & 1.01 & 1.01 \\
& 45 & 1 & 1.00 & 0.34 \\
& 53 & 1 & 1.02 & 1.81 \\
$10 \times 10$ & 15 & 1 & 1.02 & 1.56 \\
& 30 & 1 & 1.01 & 1.05 \\
& 45 & 1 & 1.01 & 1.28 \\
$15 \times 15$ & 60 & 1 & 1.01 & 0.98 \\
& 15 & 1 & 1.02 & 1.79 \\
& 30 & 1 & 1.02 & 1.51 \\
& 45 & 1 & 1.01 & 0.75 \\
$15 \times 20$ & 60 & 1 & 1.01 & 0.80 \\
& 15 & 1 & 1.00 & 0.34 \\
& 30 & 1 & 1.00 & 0.36 \\
& 45 & 1 & 1.01 & 0.80 \\
& 60 & 1 & 1.01 & 0.52 \\
\hline
\end{tabular}

the transit dose. Also, the wedge filter is actuated pneumatically (for faster movement) so that transfer time for the wedge from the OUT (parking position) to IN position remains insignificant to avoid any corrective measure.

\section{Conclusions}

A motorized wedge filter was designed, fabricated, and implemented in the Bhabhatron-II telecobalt machine. This study established that the relationship between the beam weights and effective wedge angles implemented for the motorized wedge filter of medical linacs is not directly applicable for the motorized wedge filter of telecobalt. An exclusive relation between wedge and wedge beam weight needs to be established. The dosimetric characteristics of this wedge filter were studied and evaluated. Necessary data required for its clinical implementation were generated and the wedge is commissioned for clinical treatment.

\section{References}

[1] Kumar R, Sharma SD, Reena P, Despande DD, Kannan S. Performance characteristics of indigenously developed Bhabhatron-telecobalt unit. J Med Phy 2005;30(2):41-7.

[2] Kar DC, Jayarajan K, Sharma SD, Singh M, Subrahmanyam GV. The Bhabhatron: an affordable solution for radiation therapy. Biomed Imaging Intervention J 2008;4(4):e50-12.

[3] Kinhikar RA, Sharma S, Upreti R, Tambe CM, Deshpande DD. Characterizing and configuring motorized wedge for a new generation telecobalt machine in a treatment planning system. J Med Phys 2007;32:29-33.

[4] Kinhikar RA, Patkar S, Tambe CM, Deshpande DD. On the transit dose from motorized wedge treatment in Equinox-80 telecobalt unit. J Can Res Ther 2007;3:140-2.

[5] Kinhikar RA, Sharma S, Upreti R, Tambe CM, Deshpande DD, Shrivastava SK, et al. Commissioning of motorized wedge for the first equinox-80 telecobalt unit and implementation in the Eclipse 3D treatment planning system. Australas Phys Eng Sci Med 2007;30(2):127-34. 
[6] Sahani G, Kumar M, Dash Sharma PK, Sharma DN, Chhokra K, Mishra B, et al. Compliance of Bhabhatron-II telecobalt unit with IEC standard radiation safety. J Appl Clin Med Phys 2009; 10(2):120-30.

[7] Sharma SD, Kumar R, Kar DC. IFMBE Proceedings 25 III. In: Dössel O, Schlegel WC, editors. Comprehensive evaluation of on-position leakage from source head of Bhabhatron-II telecobalt unit. WC. p. 383-5, www.springerlink.com; 2009.

[8] Tranter FW. Design of wedge filters for use with 4-MeV linear accelerator. Brit J Radiol 1957;30:329-30.

[9] Aron Bernard S, Scapicchio Michael. Design of a universal wedge filter system for a cobalt 60 unit. Am J Roentegenology 1966;96:70-4.

[10] Hubbell JH, Seltzer SM. Tables of x-ray mass attenuation coefficients and mass energy absorption coefficients $1 \mathrm{keV}$ to $20 \mathrm{MeV}$ for elements $Z=1$ to 92 and 48 additional substances of dosimetric interest. USA: National Institute of Standards and Technology (NIST); 1995.
[11] Schmidt Ernst-Ludwig, Rittler Jiirgen, Steurer Reiner. A method for quality assurance of dynamic wedge. Strahlenther Onkol 1999;175:39-41.

[12] International Commission on Radiation Units and Measurements (ICRU). Determination of absorbed dose in a patient irradiated by beams of $X$ or gamma rays in radiotherapy procedures. ICRU Rep 1976;24.

[13] Petti Paula L, Siddon Robert L. Effective wedge angles with a universal wedge. Phys Med Biol 1985;30(9):985-91.

[14] Andreo P, Burns D T, Hohlfeld K, Huq M S, Kanai T, Laitano F, et al. Absorbed dose determination in external beam radiotherapy: An international Code of Practice for dosimetry based on standards of absorbed dose to water IAEA Technical Report Series No 398 IAEA. Vienna; 2000.

[15] Philips Medical Systems Division Product Data 764, (Eindoven, The Netherlands: Philips; 1983.

[16] Zwicker RD, Shahabi S, Wu A, Stemick ES. Effective wedge angles for 6-MV wedges. Med Phys 1985;12:347-9. 